\title{
miR-143-3p regulates cell proliferation and apoptosis by targeting IGF1R and IGFBP5 and regulating the Ras/p38 MAPK signaling pathway in rheumatoid arthritis
}

\author{
ZHENGUO YANG $^{1,2}$, JIFU WANG $^{3}$, ZHUANGZHUANG PAN $^{4}$ and YIHANG ZHANG ${ }^{5}$
}

\author{
${ }^{1}$ Department of Orthopaedics, Shandong Provincial Hospital Affiliated to Shandong University, Jinan, Shandong 250021; \\ ${ }^{2}$ Department of Orthopaedics, The Second Affiliated Hospital of Shandong University of Traditional Chinese Medicine, Jinan, \\ Shandong 250001; ${ }^{3}$ Department of Orthopaedics, East Courtyard Area of General Hospital of Shandong Yankuang Group, \\ Zoucheng, Shandong 273500; ${ }^{4}$ Department of Surgery, Lixia District People's Hospital, Jinan, Shandong 250014; \\ ${ }^{5}$ Graduate Student Education Center, Shandong Academy of Medical Science, Jinan, Shandong 250062, P.R. China
}

Received June 2, 2017; Accepted January 12, 2018

DOI: $10.3892 /$ etm.2018.5907

\begin{abstract}
It has been demonstrated that the deregulation of microRNAs (miRNAs) affects the development of rheumatoid arthritis (RA). The primary objective of the current study was to determine the role of miR-143-3p in the progression of RA. The expression of miR-143-3p in synovium taken from patients with RA was assessed by reverse transcription-quantitative polymerase chain reaction. The expression of miR-143-3p was higher in synovium tissues of RA than that of osteoarthritis (OA). The decreased expression of miR-143-3p suppressed cell proliferation and promoted apoptosis in vitro. In addition, inhibition of miR-143-3p decreased levels of inflammatory cytokines, as determined by an enzyme-linked immunosorbent assay. IGF1R and IGFBP5 were found to be the target genes of miR-143-3p, and it was demonstrated that miR-143-3p regulated the proliferation and apoptosis of MH7A cells by targeting IGF1R and IGFBP5. Furthermore, TNF- $\alpha$ treatment stimulated the Ras/p38 mitogen activated protein kinase (MAPK) signaling pathway, whereas miR-143-3p inhibition suppressed it. The results of the current study indicate that miR-143-3p may regulate cell proliferation and apoptosis by targeting IGF1R and IGFBP5 expression and regulating the Ras/p38 MAPK signaling pathways. Therefore, miR-143-3p may be a novel therapeutic target in RA.
\end{abstract}

Correspondence to: Professor Yihang Zhang, Graduate Student Education Center, Shandong Academy of Medical Science, 18777 Jingshi Road, Jinan, Shandong 250062, P.R. China E-mail: yihangzhang06@126.com

Key words: microRNA-143-3p, rheumatoid arthritis, synovial fibroblasts, insulin-like growth factor 1 receptor, insulin-like growth factor binding protein 5

\section{Introduction}

Rheumatoid arthritis (RA) is a chronic autoimmune inflammatory disease in which patient experience clinical symptoms of articular pain, cartilage degradation, narrow joint space and loss of joint flexibility (1-3). Osteoclasts, which are the cells primarily responsible for bone dissolution and resorption, serve a critical role in joint destruction by upregulating inflammation and directly destroying the adjacent bone (4). Osteoclast precursors and mature osteoclasts, which also serve an important role in the inflammatory response are localized at arthritic bone erosions (5). Among the Chinese population, the incidence rate of RA is $0.24-0.5 \%$ and RA is more prevalent in women than men (6).

Synovial fibroblasts serve a key role in the pathogenesis of RA and their tumor-like proliferation leads to the development of synovial hyperplasia (7). During RA, activated synovial fibroblasts accumulate in the hyperplastic synovium of patients with RA. Higher levels of inflammatory cytokines, chemotactic factors and matrix metalloproteinase mediate inflammation and degrade cartilage, which eventually leads to the destruction of joints (8). Several studies have been conducted to explore the association between synovial fibroblasts and the regulation of inflammatory pathways in the RA synovium (9-11); however, the precise mechanism of action by which this occurs remains unknown (12).

MicroRNAs (miRNAs) are a class of non-coding RNAs that regulate gene expression by binding to the 3'untranslated region (UTR) of their target mRNAs. They serve critical roles in numerous diseases, including different types of cancer, inflammatory and neurological diseases (13-15). Studies have suggested that miRNAs are involved in the pathogenesis of many diseases, such as RA and may therefore be developed as potential therapeutic targets in the treatment of RA (16-18). miR-143-3p is a type of miRNA that has been implicated in numerous diseases, including age-related defective muscle regeneration, gastric cancer and esophageal squamous cell carcinoma (19). However, to the best of our knowledge, the key roles and regulatory mechanisms of miR-143-3pin RA remain unknown. 
In the present study, the expression of miR-143-3p in RA synovial tissues was measured. The regulation of insulin-like growth factor 1 receptor (IGF1R) and insulin-like growth factor-binding protein 5 (IGFBP5) by miR-143-3p is considered to be a key mechanism that mediates the age-related changes in satellite cell function (20). Furthermore, it has been demonstrated that the p38 mitogen-activated protein kinase (MAPK) pathway serves a crucial role in the induction and maintenance of chronic inflammation in RA (21). Therefore, the present study investigated the association between miR-143-3p, and IGF1R and IGFBP5, as well between miR-143-3p and the Ras/p38 MAPK signaling pathway, to elucidate the potential regulatory mechanism of miR-143-3p in RA. The MH7A cell line was used as an in vitro model system.

\section{Materials and methods}

Patients. Synovia were obtained from 5 patients with RA and 5 patients with osteoarthritides (OA) that fulfilled the American College of Rheumatology Criteria for RA or OA (22), as well as one patient undergoing reconstruction of the anterior cruciate ligament (as a control). Synovial tissues were collected from 3 patients with RA as they underwent total knee arthroplasty (TKA) and 2 patients with RA as they underwent synovectomy. All synovial tissue samples taken from patients with OA were collected during TKA. The mean age of patients with RA and OA were 62.9 \pm 10.9 (39-78) and $71.6 \pm 4.9$ (72-81) years, respectively. As the mean age of patients in the two groups differed, a multivariate logistic regression model with adjustment for age was used to evaluate miR-143-3p expression in the synovium of patients with RA as well as those with OA. Among the patients with RA, there were 2 males and 3 females; however, all patients with OA were female. A further patient (male, 45 years old) undergoing leg amputation but with a normal knee joint was included as the control. The synovial tissues were harvested from the control patient during the amputation surgery. The present study was approved by the Ethics Committee of Shandong Academy of Medical Science (Jinan, China) and written informed consent was obtained from all patients that participated in the study.

Cell culture. The human RA synovial cell line MH7A was procured from the American Type Culture Collection (Manassas, VI, USA). MH7A cells were stained positively for intercellular adhesion molecule-1 (ICAM-1), interleukin (IL)-1R, cluster of differentiation (CD)16, CD40, CD80 and CD95 (23); and have been previously used to investigate the molecular mechanisms underlying RA (23). Cells were maintained in RPMI 1640 medium (Hyclone; GE Healthcare, Logan, UT, USA), supplemented with $10 \%$ fetal bovine serum (Gibco; Thermo Fisher Scientific, Inc., Waltham, MA, USA) and $1 \%$ penicillin/streptomycin (1:100, Sigma-Aldrich; Merck $\mathrm{KGaA}$, Darmstadt, Germany), at $37^{\circ} \mathrm{C}$ in a relative humidity of $95 \%$ and in $5 \% \mathrm{CO}_{2}(24)$.

Cell transfection. To assess the effects of miR-143-3p abnormal expression on MH7A cells, the cells were transfected with miR-143-3p mimic, miR-143-3p inhibitor or their controls (mimic NC or inhibitor NC). Briefly, MH7A cells $\left(1 \times 10^{5}-2 \times 10^{5}\right)$ were transfected with 90 pmol hsa-miR-143-3p mimic (Takara, Okinawa, Japan) and the mimic control (mimic NC; 90 pmol) (Takara) three times over 7 days. Cells were also transfected with mirVana $^{\mathrm{TM}}$ hsa-miR-143-3p inhibitor (Thermo Fisher Scientific, Inc.) (150 pmol), inhibitor NC (150 pmol), small interfering (si)RNA against IGF1R (si-IGFR; 100 pmol) or IGFBP5 (si-IGFBP5; 100 pmol) or the si-NC control (100 pmol) (Thermo Fisher Scientific, Inc.) for 72 h. All transfections were performed using Lipofectamine ${ }^{\circledR}$ RNAiMAX Transfection Reagent (Thermo Fisher Scientific, Inc.) following the manufacturer's protocol. The cells in the control group received no additional treatment. The sequences of the miRs and siRNA used were as follows: miR-143-3p mimic sense 5'-GGUGCAGUGCUGCAUCUCUGGU-3' and anti-sense, 5'-CAGAGAUGCAGCACUGCACCUU-3'; mimic NC sense 5'-UCACAACCUCCUAGAAAGAGUAGA-3'; mimic NC antisense 5'-UCUACUCUUUCUAGGAGGUUG UGA-3'; miR-143-3p inhibitor 5'-ACCAGAGAUGCAGCA CUGCACC-3'; inhibitor NC, 5'-UCUACUCUUUCUAGG AGGUUGUG-3'. si-IGFR 5'-GCGGAGAGAUGUCAUGCA AGU-3'; si-IGFBP5 5'-GGAUCUGUCUCCUCCUCUAGC-3'. si-NC: 5'-UUCUUCGAAGGUGUCACGUTT-3'.

Cell counting kit $8(C C K-8)$ assay. MH7A cells were seeded in 96-well plates at 5,000 cells/well for $72 \mathrm{~h}$ transfected with miR-143-3p inhibitor, si-IGF1R, si-IGFBP5 or corresponding controls (inhibitor NC or si-NC) for $24 \mathrm{~h}$. Subsequently, cells were treated with tumor necrosis factor (TNF)- $\alpha(10 \mathrm{ng} / \mathrm{ml}$; Sigma-Aldrich; Merck KGaA) at room temperature for $24 \mathrm{~h}$ to construct a model of RA. The cells in the control group were treated with normal RPMI 1640 medium. Subsequently, CCK-8 solution (Invitrogen; Thermo Fisher Scientific, Inc.) was added to each well and plates were incubated at $37^{\circ} \mathrm{C}$ for $2 \mathrm{~h}$. The absorbance of each well was measured at $450 \mathrm{~nm}$ using a microplate reader (25).

Flow cytometric analysis of apoptosis. Cells or corresponding controls were harvested following transfection with miR-143-3p inhibitor, si-IGF1R or si-IGFBP5 for $24 \mathrm{~h}$. Cells were treated with TNF- $\alpha$, washed twice with pre-chilled PBS and resuspended in $100 \mu \mathrm{l}$ binding buffer at a concentration of $1 \times 10^{6}$ cells $/ \mathrm{ml}$. Annexin V and propidium iodide (PI) double-staining was performed using an Annexin V-fluorescein isothiocyanate Apoptosis Detection kit (BD Biosciences, San Jose, CA, USA) according to the manufacturer's protocol. Apoptosis analysis was performed using the BD LSRII Flow Cytometer System with FACSDiva Software version 6.0 (BD Biosciences) within $1 \mathrm{~h}$ (25).

Vector construction, target prediction and luciferase reporter assay. The potential target genes of miR-143-3p were analyzed by TargetScan Human 7.0 (targetscan.org/vert_71/). A cut-off value of 0.7 was applied to predict the target genes. To develop a luciferase reporter construct, the 3'-UTR fragments of IGF1R or IGFBP5, which contained putative binding sites for miR-143-3p, were inserted downstream of firefly luciferase in the pGL3 vector (Promega Corporation). Mutant 3'-UTR, which carried the mutated sequence in the complementary site for miR-143-3p, was generated using the polymerase chain reaction (PCR) method (26) and inserted downstream of firefly luciferase in a separate pGL3 vector. 293A cells 
$\left(1 \times 10^{5}\right.$; American Type Culture Collection) were cultured in a 48-well plate were co-transfected with miR-143-3p with a luciferase reporter comprising wild-type or mutant 3'-UTR of the target gene. The luciferase assay was performed as previously reported (26). 293A cells were co-transfected with miRs and wild-type 3'-UTR or mutant 3'-UTR luciferase reporter, using pRL-TK (Promega Corporation) as a control vector. Following $48 \mathrm{~h}$ transfection, luciferase activity was measured using the Dual Luciferase Assay kit (Promega Corporation) with a $\beta$-counter luminometer. Relative luciferase activity was calculated as the ratio of the raw firefly luciferase activity and Renilla luciferase activity (27).

Reverse transcription-quantitative PCR (RT-qPCR). Total RNA was isolated from MH7A cells using the commercial total RNA miniprep kit (Axygen; Corning Inc., Corning, NY, USA) according to the manufacturer's protocol. Each sample was reverse transcribed using a cDNA synthesis kit (Takara). qPCR was performed using SYBR Green PCR Premix Ex Taq II reagents (Takara) on a Light Cycler 480 II real-time system (Roche Diagnostics, Indianapolis, IN, USA). The house-keeping gene GAPDH was used for normalization. The mRNA expression was quantified by the comparative $2^{-(\Delta \Delta C q)}$ method (28). The primers used for target amplification were as follows: MiR-143 forward, 5'-TGAGATGAAGCACTG TAGCTC-3' and reverse, 5'-TGGTGTCGTGGAGTCG-3'; U6 forward, 5'-CTCGCTTCGGCAGCACA-3' and reverse, 5'-AACGCTTCACGAATTTGCGT-3'; B-cell lymphoma (Bcl)-2 forward, 5'-GATGCAGTGCCGGCCTAAG-3' and reverse, 5'-TTCTCTTGTACGCACGAGCT-3'; Bax forward, 5'-CTGAGCTGACCTTGGAGC-3' and reverse, 5'-GAC TCCAGCCACAAAGATG-3'; Caspase-3 forward, 5'-ACC GATGTCGATGCAGCTAA-3' and reverse, 5'-AGGTCC GTTCGTTCCAAAAA3'. GAPDH forward, 5'-CCACCC ATGGCAAATTCCATGGCA-3' and reverse, 5'-TCTAGA CGGCAGGTCAGGTCCACC-3'; IGF1R forward, 5'-GCG AGCTCTCTGGGATAGAAATGTTTAGGTGTA-3' and reverse, 5'-GCAAGCTTCAGGTGCTGAGAAAGGTGA GATGT-3'; IGFBP5 forward, 5'-ACGCGTCGACATGGG CTCCTTCGTGCAC3' and reverse, 5'-CGCGGATCCATC ACTCAACGTTGCTGCTG-3'. The thermocycling conditions were as follows: $95^{\circ} \mathrm{C}$ for $1 \mathrm{~min}$ followed by 35 cycles of $95^{\circ} \mathrm{C}$ for $10 \mathrm{sec}$ and $58^{\circ} \mathrm{C}$ for $40 \mathrm{sec}$, with a final extension step of $10 \mathrm{~min}$ at $68^{\circ} \mathrm{C}$.

Enzyme-linked immunosorbent assay (ELISA). (29). The culture medium was collected and the concentration of the cytokines was determined using commercial ELISA kits for IL-1 $\beta$ (ab100704), IL-6 (ab46042), IL-8 (ab46032), MMP-1 (ab100603) and MMP-13 (ab100605) (all Abcam, Cambridge, UK) following the manufacturer's protocol. Values were calculated on the basis of a standard curve constructed for each assay.

Western blot analysis. Cells were solubilized with radioimmunoprecipitation assay lysis buffer (Thermo Fisher Scientific, Inc.) and protein concentration was measured using a BCA kit (Thermo Fisher Scientific, Inc.). Approximately $50 \mu \mathrm{g}$ of protein from each sample was separated by $12 \%$ SDS-PAGE and transferred to a polyvinylidene
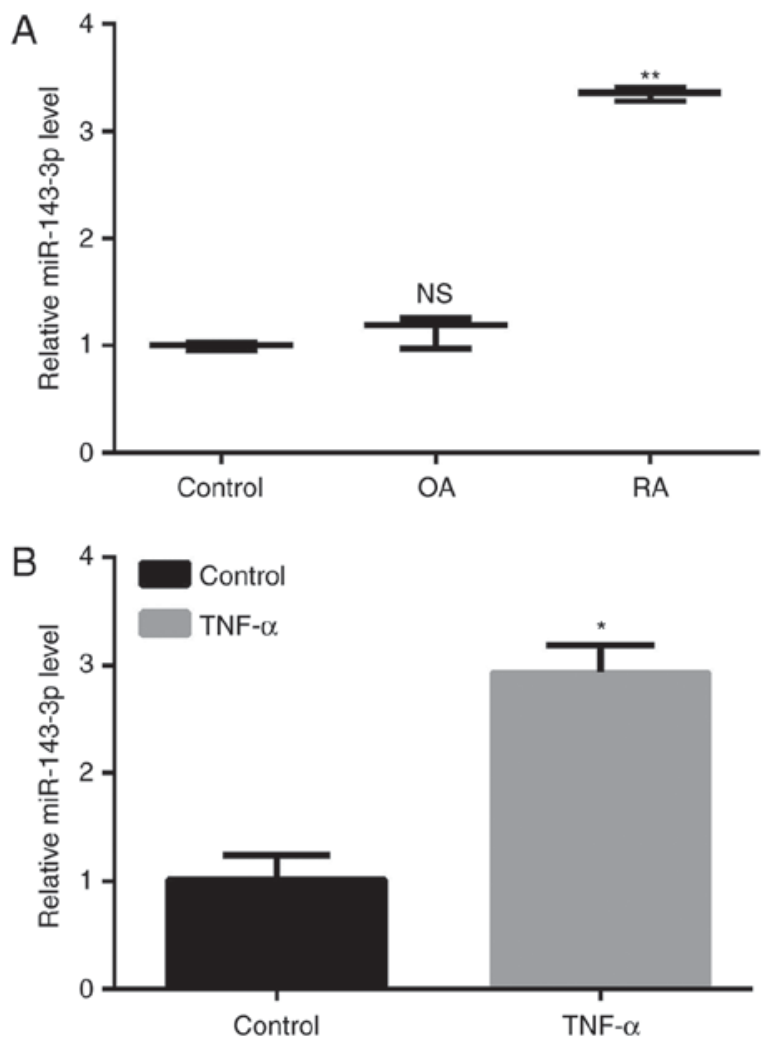

Figure 1. The expression of miR-143-3p in RA tissue and cells. (A) The expression of miR-143-3p in patients with RA compared with patients with OA and a healthy control. (B) The expression of miR-143-3p in a model of RA induced by treatment with TNF- $\alpha$. Data are presented as the mean \pm standard deviation from at least three independent experiments. ${ }^{*} \mathrm{P}<0.05$ and ${ }^{* *} \mathrm{P}<0.01$ vs. control. miR, microRNA; NS, non-significant; OA, osteoarthritis. RA, rheumatoid arthritis; TNF, tumor necrosis factor.

fluoride membrane (EMD Millipore, Burlington, MA, USA). Following blocking with 5\% bovine serum albumin (1:100; Sigma-Aldrich; Merck KGaA) in Tris-buffered saline with Tween for $2 \mathrm{~h}$ at room temperature, membranes were incubated with Bcl-2 (ab178529), Bax (ab53154), pro-caspase-3 (ab32150) and active-caspase-3 (ab181418), phosphorylated (p)-p38 (ab4822), p38 (ab31828) and Ras (ab52939) primary antibodies at a dilution of 1:1,000 overnight at $4^{\circ} \mathrm{C}$ (all Abcam, Cambridge, UK), followed by incubation with goat anti-rabbit horseradish peroxidase conjugated secondary antibodies (at a dilution of 1:2,000; ab191866; Abcam) for $1 \mathrm{~h}$ at room temperature. GAPDH (ab8245; dilution 1:2,000; Abcam) was used as an internal control. Protein blots were visualized and analyzed using a chemiluminescence system (Bio-Rad Laboratories, Inc., Hercules, CA, USA) and autoradiography films (Kodak Image Station 440; Kodak, Rochester, NY, USA).

Statistical analysis. Data are presented as the mean \pm standard deviation from at least three independent experiments. All statistical analyses were performed using SPSS 16.0 (SPSS, Inc., Chicago, IL, USA). Student's t test was performed to assess whether differences between two groups was significant, whereas one-way analysis of variance followed by a post-hoc Tukey's test was performed to evaluate whether differences among three or more groups were significant. 


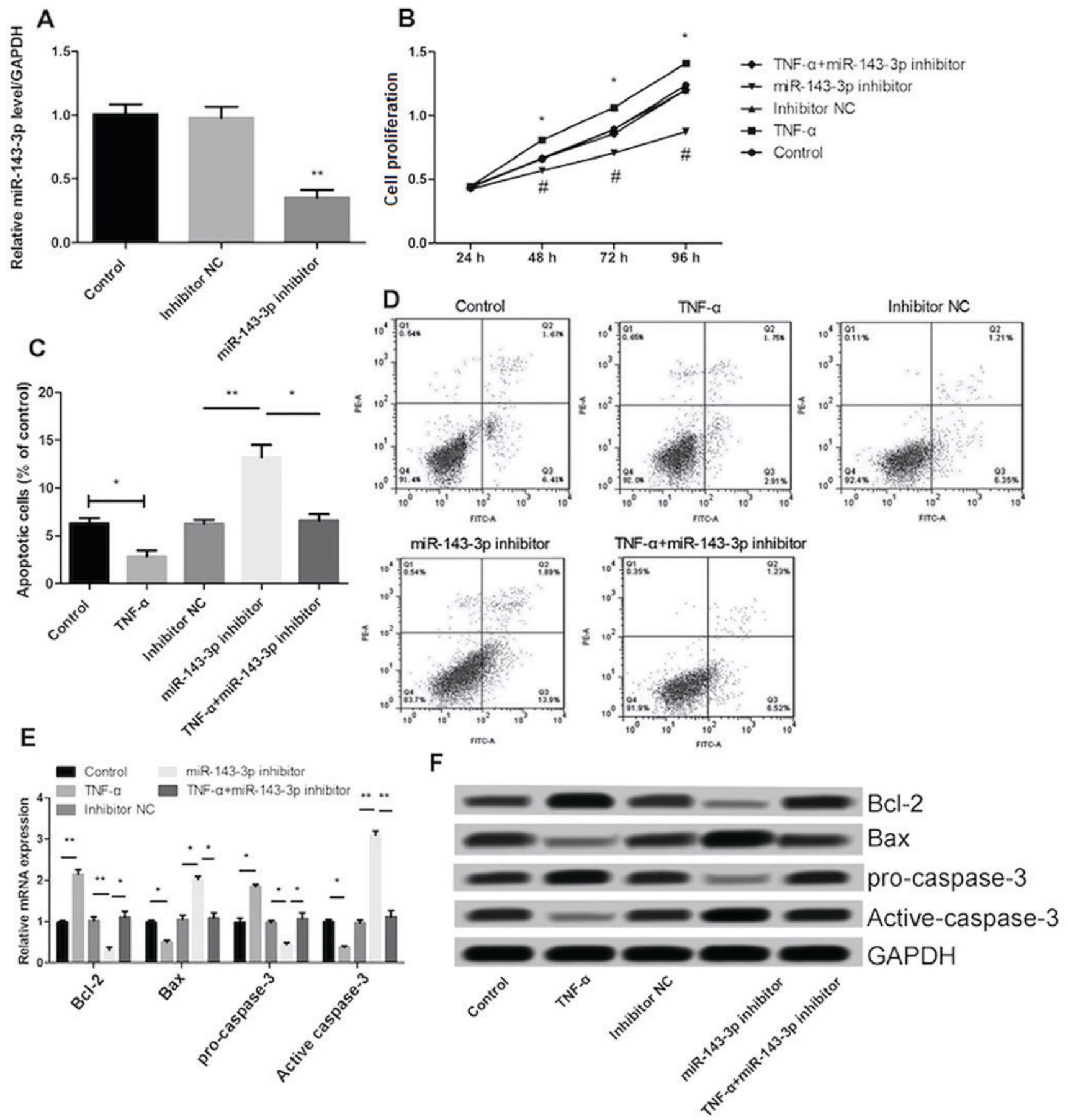

Figure 2. Inhibition of miR-143-3p reduces cell proliferation and promotes cell apoptosis. (A) Transfection of miR-143-3p inhibitor in MH7A cells. ${ }^{* *} \mathrm{P}<0.01$ vs. control. (B) Effect of TNF- $\alpha$ treatment and transfection with miR-143-3p inhibitor on cell proliferation and (C and D) apoptosis. (E and F) Effect of TNF- $\alpha$ treatment and miR-143-3p inhibition on the expression of Bax, Bcl-2, pro-caspase-3 and active caspase-3. Data are presented as the mean \pm standard deviation from at least three independent experiments. " $\mathrm{P}<0.05$ and ${ }^{* *} \mathrm{P}<0.01$ vs. control; ${ }^{*} \mathrm{P}<0.05$ vs. inhibitor $\mathrm{NC}$ group. TNF, tumor necrosis factor; miR, microRNA; $\mathrm{OD}$, optical density; $\mathrm{NC}$, negative control.

$\mathrm{P}<0.05$ was considered to indicate a statistically significant difference.

\section{Results}

Analysis of miR-143-3p expression in RA tissues and cells. The expression of miR-143-3p in RA was significantly higher than in patients with $\mathrm{OA}$ and the control $(\mathrm{P}<0.01$; Fig. 1A). MH7A cells were treated with $10 \mathrm{ng} / \mathrm{ml} \mathrm{TNF-} \alpha$ to construct a model of RA and the results demonstrated that the expression of miR-143-3p was significantly increased in TNF- $\alpha$-induced RA cells compared with the untreated control cells $(\mathrm{P}<0.05$, Fig. 1B).

miR-143-3p inhibitor reduces cell proliferation and promotes apoptosis. Transfection of the miR-143-3p inhibitor in MH7A cells significantly decreased miR-143-3p expression $(\mathrm{P}<0.01)$, indicating that transfection was successful (Fig. 2A). 

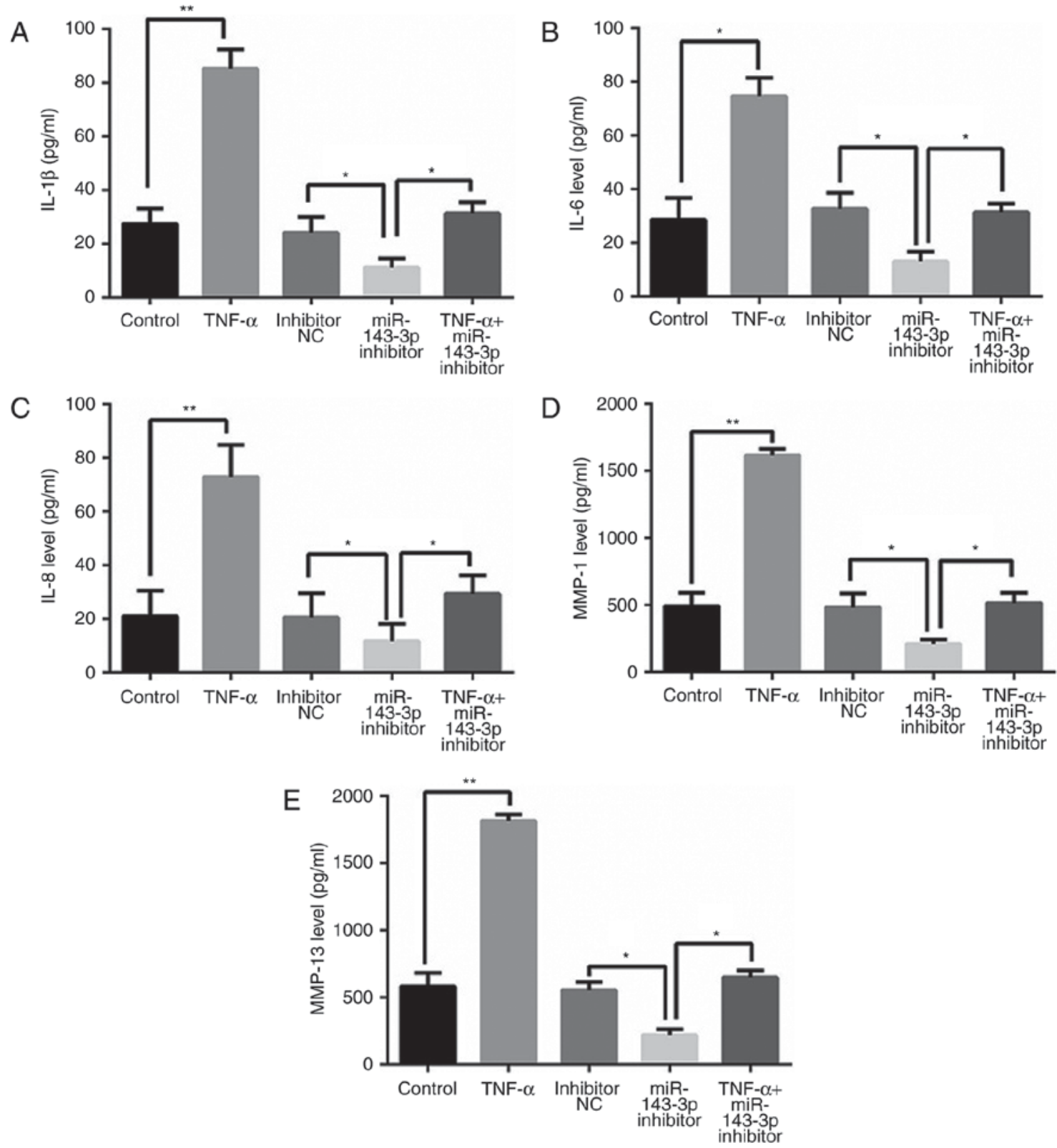

Figure 3. Inhibition of miR-143-3p suppresses the expression of inflammatory factors. Levels of (A) IL-1 $\beta$, (B) IL-6, (C) IL-8, (D) MMP-1 (E) and MMP-13. Data are presented as the mean \pm standard deviation from at least three independent experiments. ${ }^{*} \mathrm{P}<0.05$ and ${ }^{* *} \mathrm{P}<0.01$. miR, microRNA; NC, negative control; IL, interleukin; MMP, matrix metalloproteinase.

Treatment with TNF- $\alpha$ significantly increased the proliferation and inhibited the apoptosis of MH7A cells $(\mathrm{P}<0.05$; Fig. 2B and C). The effect of TNF- $\alpha$ on cell proliferation and apoptosis was significantly reversed following inhibition of miR-143-3p ( $\mathrm{P}<0.05$; Fig. 2B-D). In addition, the results demonstrated that transfection with the miR-143-3p inhibitor significantly promoted the expression of Bax and inhibited the expression of Bcl-2 ( $\mathrm{P}<0.01$; Fig. $2 \mathrm{E}$ and $\mathrm{F})$. The expression of cell apoptosis-associated proteins, including Bcl-2 and pro-caspase- 3 was significantly increased in the TNF- $\alpha$ group $(\mathrm{P}<0.01)$ compared with the control group, whereas the expression of Bax and active-caspase-3 were significantly decreased $(\mathrm{P}<0.05$; Fig. 2E and F). Furthermore, following transfection with miR-143-3p inhibitor, the expression of pro-caspase-3 was significantly inhibited and the expression of active-caspase- 3 was significantly promoted.
miR-143-3p inhibitor inhibits levels of inflammatory factors. As presented in Fig. 3, TNF- $\alpha$ treatment significantly increased levels of inflammatory factors, including interleukin (IL)-1 $\beta$, IL-6, IL-8, matrix metalloproteinase (MMP)-1 and MMP-13 $(\mathrm{P}<0.05)$. However, cells transfected with miR-143-3p inhibitor exhibited significant decreases in levels of these inflammatory factors, compared with control cells $(\mathrm{P}<0.05$; Fig. 3).

Prediction and examination of the targeting effects of $m i R-143-3 p$. The TargetScan Human 7.0 (targetscan. org/vert_71/) was used to analyze the potential target gene of miR-143-3p, and the sequence analysis data indicated that IGF1R and IGFBP5 were targets of miR-143-3p (Fig. 4A and B). The results of the luciferase reporter assay confirmed that the 3 '-UTR regions of IGF1R and IGFBP5 possess hsa-miR-143-3p binding sites $(\mathrm{P}<0.05$; 
A

Position 2664-2670 of IGF1R $3^{\prime}$ UTR

hsa-miR-143-3p

B

Position 91-98 of IGFBP5 $33^{\prime}$ UTR

hsa-miR-143-3p

\author{
Predicted consequential pairing of target \\ region (top) and miRNA (bottom) \\ 5'-ACAAAAGAAUA CAUCUCA C-3' \\ 3'-UGUCACGAA-- GUAGAG U-5'
}

Predicted consequential pairing of target region (top) and miRNA (bottom)

5'-GCCACUCAUU UCAUCUC A-3'

3'-GAUGUCACGA AGUAGAG U-5'

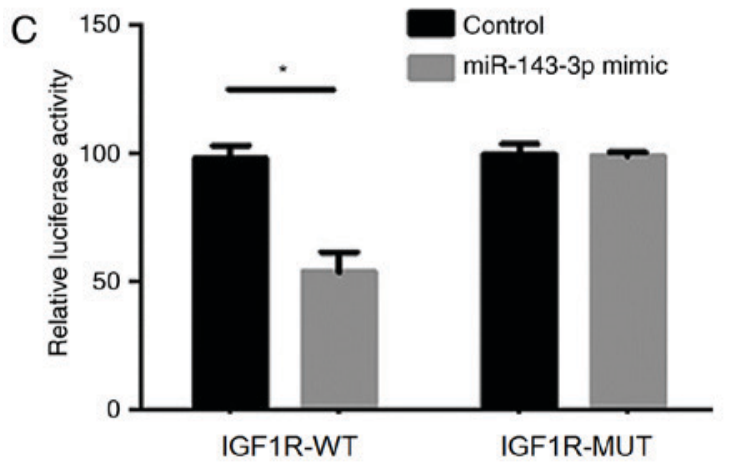

E
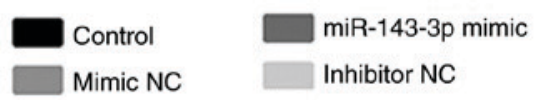

miR-143-3p inhibitor

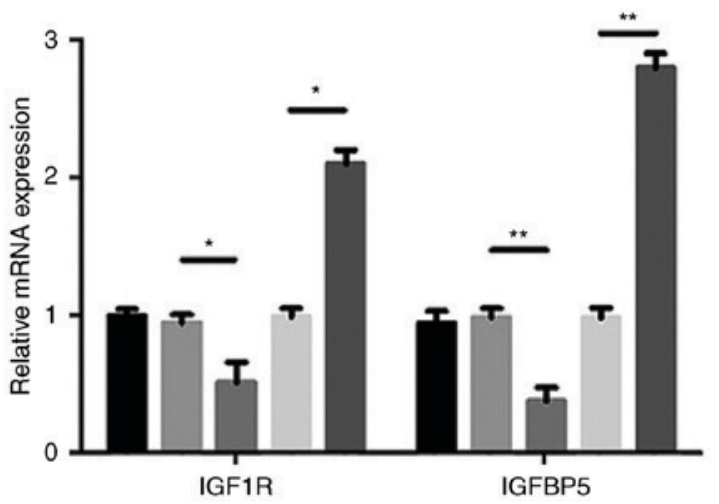

$\mathrm{F}$

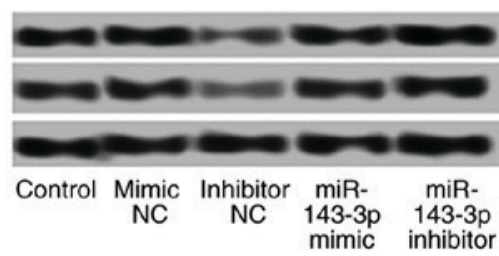

IGF1R

IGFBP5

GAPDH

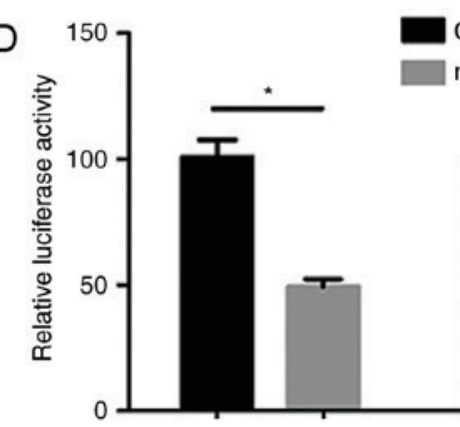

IGFBP5-WT
Control

miR-143-3p mimic

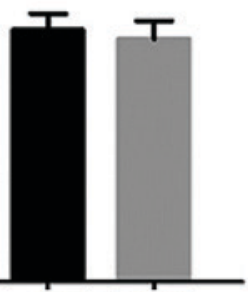

IGFBP5-MUT

G
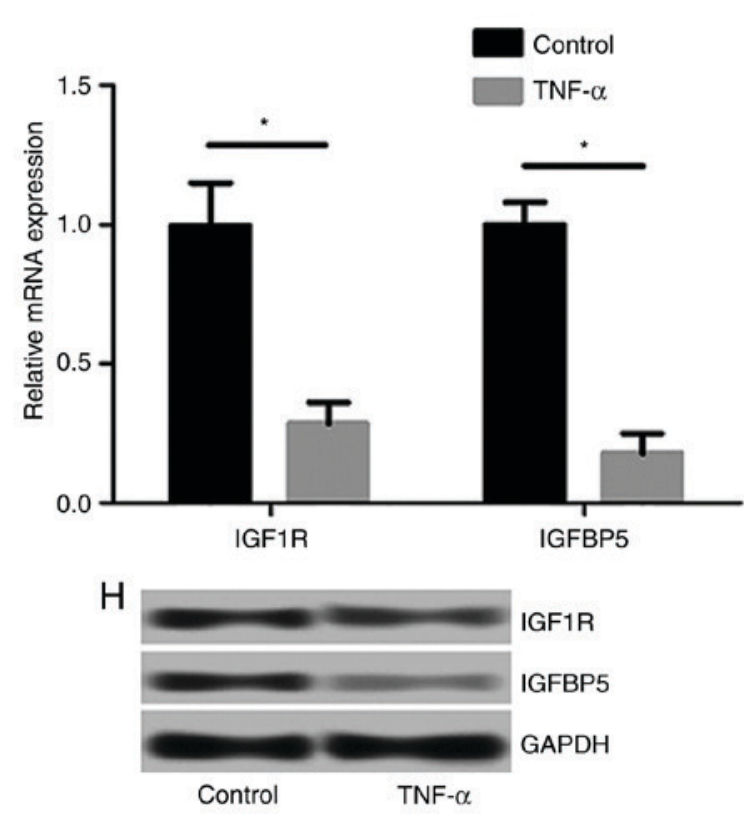

Figure 4. The prediction and examination of the targeting effects of miR-143-3p. (A) IGF1R and (B) IGFBP5 are target genes of miR-143-3p. Relative luciferase activity of (C) IGF1R and (D) IGFBP5. (E) The expression of IGF1R and IGFBP5 mRNA following transfection with miR-143-3p mimic and inhibitor. (F) The expression of IGF1R and IGFBP5 protein following transfection with miR-143-3p mimic and inhibitor. (G) The expression of IGF1R and IGFBP5 mRNA following treatment with TNF- $\alpha$. $(\mathrm{H})$ The expression of IGF1R and IGFBP5 protein following treatment with TNF- $\alpha$. Data are presented as the mean \pm standard deviation from at least three independent experiments. " $\mathrm{P}<0.05$ and ${ }^{* *} \mathrm{P}<0.01$. UTR, untranslated region; miR, microRNA; TNF, tumor necrosis factor; NC, negative control; IGF1R, insulin-like growth factor 1 receptor; IGFBP5, insulin-like growth factor-binding protein 5.

Fig. 4C and D). Moreover, the expression levels of IGF1R and IGFBP5 were significantly inhibited following transfection of miR-143-3p mimics $(\mathrm{P}<0.05)$, whereas the transfection of miR-143-3p inhibitors significantly increased the levels of
IGF1R and IGFBP5 (P<0.01; Fig. 4E and F). Reduced levels of IGF1R and IGFBP5 mRNA and protein expression were observed in RA models following treatment with TNF- $\alpha$ $(\mathrm{P}<0.05$; Fig. 4G and $\mathrm{H})$. 

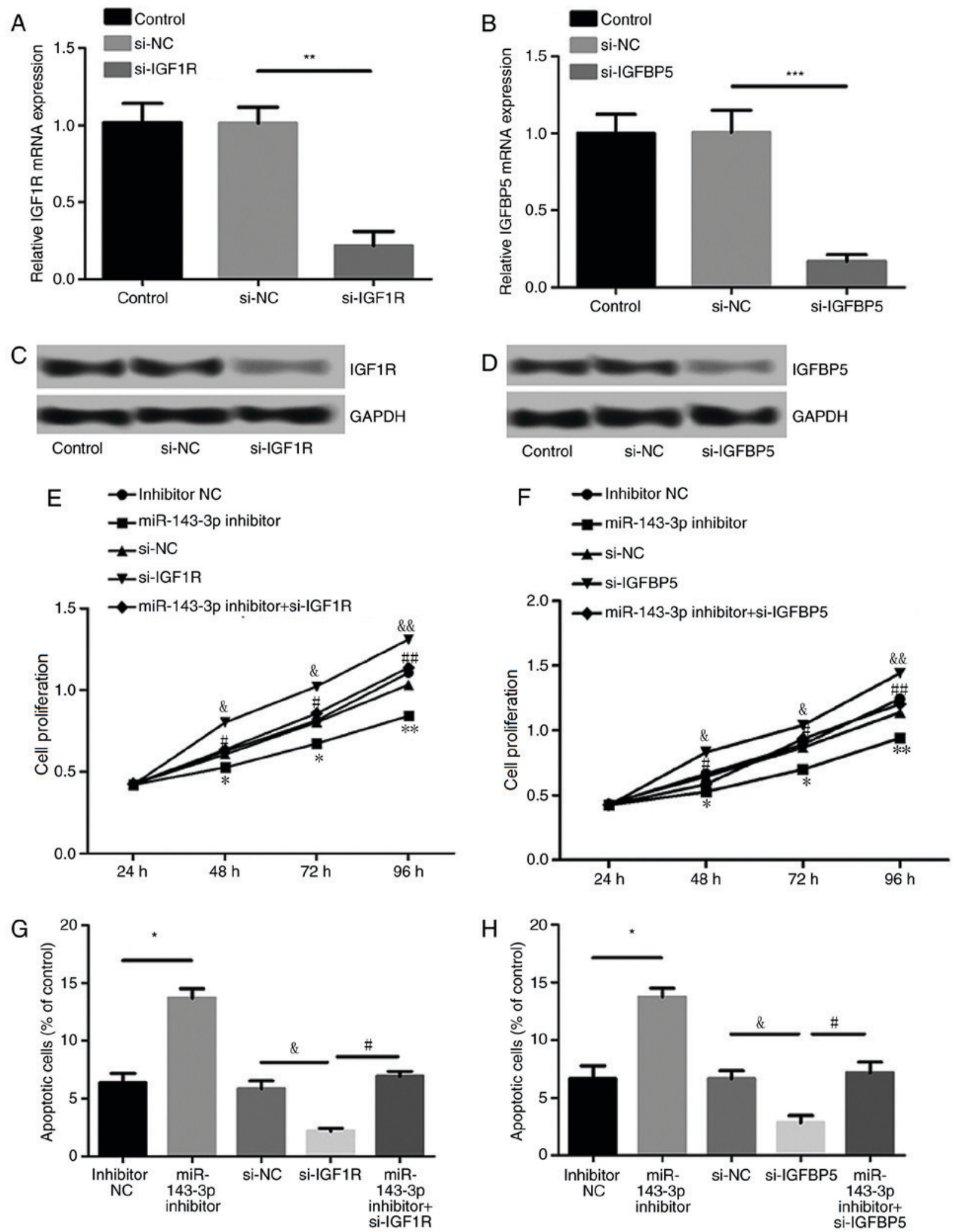

Figure 5. Effect of IGF1R or IGFBP5 suppression on cell growth and apoptosis. (A-D) Transfection efficiency of si-IGF1R and si-IGFBP5. $\mathrm{P}<0.05$, ${ }^{* *} \mathrm{P}<0.01$ and ${ }^{* * *} \mathrm{P}<0.001$. (E-H) Effect of silencing IGF1R and IGFBP5 expression on cell proliferation and apoptosis. Data are presented as the mean \pm standard deviation from at least three independent experiments. ${ }^{*} \mathrm{P}<0.05 ;{ }^{* *} \mathrm{P}<0.01$ and ${ }^{* * * *} \mathrm{P}<0.001$ vs. the inhibitor $\mathrm{NC}$ group. ${ }^{\text {\& }} \mathrm{P}<0.05$ and ${ }^{\text {\&\&}} \mathrm{P}<0.01$ vs. the si-NC group; ${ }^{\#} \mathrm{P}<0.05$ and ${ }^{\# \#} \mathrm{P}<0.01$ vs. the si-IGF1R group or si-IGFBP5 group. miR, microRNA; si, small interfering; NC, negative control; IGF1R, insulin-like growth factor 1 receptor; IGFBP5, insulin-like growth factor-binding protein 5; OD, optical density.

Effects of IGFIR and IGFBP5 suppression on cell proliferation and apoptosis. As presented in Fig. 5A-D, levels of IGF1R and IGFBP5 expression were significantly suppressed following transfection with siRNAs against IGF1R and IGFBP5, respectively $(\mathrm{P}<0.01)$, indicating efficient transfection. Furthermore, suppression of IGF1R or IGFBP5 
expression significantly reversed the effect of miR-143-3p inhibition on MH7A cell proliferation and apoptosis $(\mathrm{P}<0.05$; Fig. 5E-H). These results indicate that miR-143-3p regulates MH7A cell proliferation and apoptosis by targeting IGF1R or IGFBP5.

miR-143-3p inhibitor suppressed the expression of Ras and $p-p 38 / p 38$. The effect of TNF- $\alpha$ treatment and the miR-143-3p inhibitor on the Ras/p38 signaling pathway was investigated. The results demonstrated that TNF- $\alpha$ treatment significantly increased the expression of Ras $(\mathrm{P}<0.01)$ and $\mathrm{p}-\mathrm{p} 38 / \mathrm{p} 38$ $(\mathrm{P}<0.001 ;$ Fig. 6). These increases were significantly reversed by the miR-143-3p inhibitor, indicating that the miR-143-3p inhibitor inhibits the Ras/p38 MAPK signaling pathway in a TNF- $\alpha$-induced RA model.

\section{Discussion}

The present study revealed that miR-143-3p was highly expressed in RA tissue. The inhibition of miR-143-3p suppressed the proliferation of MH7A cells and promoted their apoptosis. It was confirmed that IGF1R and IGFBP5 are targets of miR-143-3p and that miR-143-3p regulated the proliferation and apoptosis of MH7A cells by targeting IGF1R and IGFBP5. Ultimately, the miR-143-3p inhibitor suppressed the Ras/p38 MAPK signaling pathway in TNF- $\alpha$-induced RA models. These results suggest that miR-143-3p serves a key role in the development of RA.

It has been reported that miRNAs are able to target proto-oncogenes, including $\mathrm{Bcl}-2$, Ras or $\mathrm{c}-\mathrm{Myc}$ (30). Bcl-2 and $\mathrm{Bax}$, which are members of the anti-apoptotic $\mathrm{Bcl}-2$ family, serve a critical role in regulating apoptosis and are able to inhibit the activation of caspase-3 (31). Zhang and $\mathrm{Li}$ (32) indicated that miR-143-3p regulates the proliferation of cytokine-induced killer cells. The results of the present study indicated that cells transfected with the miR-143-3p inhibitor exhibited enhanced expression of Bax, but decreased expression of Bcl-2, that miR-143-3p promotes cell apoptosis. In addition, RA is a self-maintaining inflammatory disease, in which the destruction of the adjacent bone is induced by inflammation (33). Studies have demonstrated that inflammatory cytokines, including IL-1 $\beta$, IL- 6 , IL- 8 , MMP- 1 and MMP-13, serve a key role in the pathogenesis of RA $(34,35)$. The results of the present study indicated that inhibition of miR-143-3p significantly inhibited the production of these inflammatory cytokines.

In addition, the present study indicated that IGF1R and IGFBP5 are target genes of miR-143-3p. It has been reported that IGF-1R signaling contributes to $\mathrm{T}$ cell-dependent inflammation in RA (35). Furthermore, it has been suggested that MMP-13 and IGFBP5 are important factors that mediate the development of OA (36). In the present study, it was demonstrated that miR-143-3p regulates the proliferation and apoptosis of MH7A cells by targeting IGF1R or IGFBP5, implying that miR-143-3p is associated with IGF1R and IGFBP5 in RA.

The MAPK signaling pathway, which involves $\mathrm{p} 38$ and c-Jun $\mathrm{N}$ terminal kinase (JNK) $1 / 2$, serves an important role in various cellular processes, including inflammation, proliferation, migration and adhesion (37-39). MAPKs
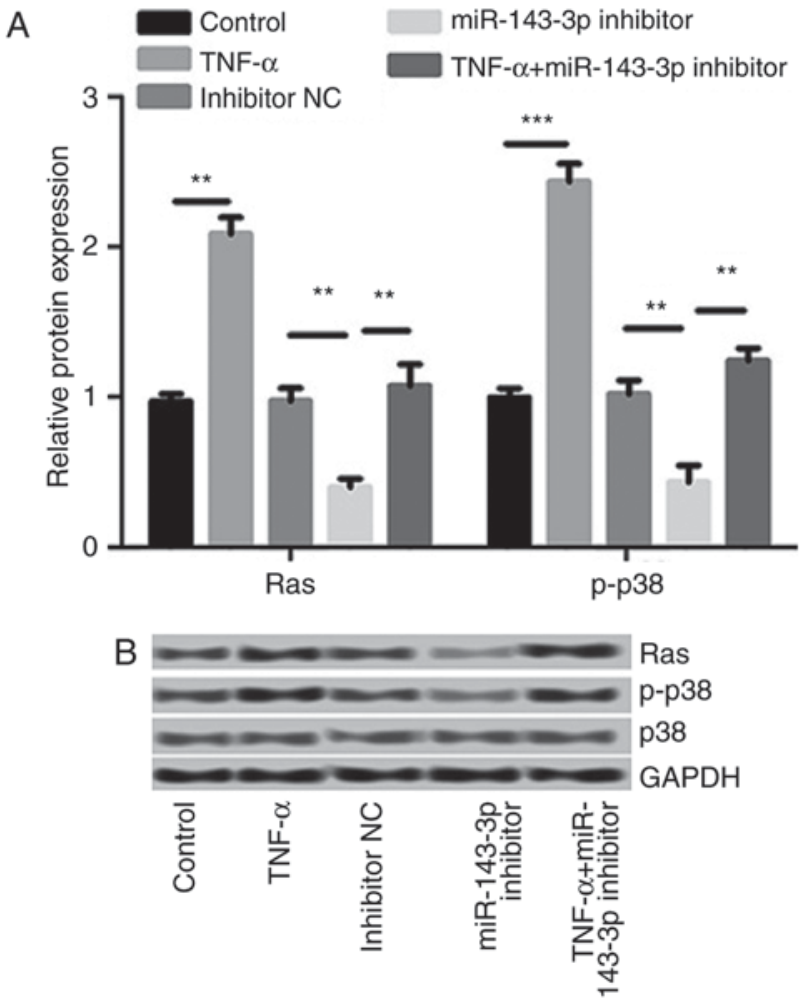

Figure 6. The effects of TNF- $\alpha$ treatment and miR-143-3p inhibition on the Ras/p38 MAPK signaling pathway. (A) Levels of Ras and p-p38/p38 mRNA. (B) Levels of Ras and p-p38/p38 protein. Data are presented as the mean \pm standard deviation from at least three independent experiments. ${ }^{* *} \mathrm{P}<0.01$ and ${ }^{* * *} \mathrm{P}<0.001$. $\mathrm{p}-$, phosphorylated; miR, microRNA; TNF, tumor necrosis factor; $\mathrm{NC}$, negative control.

participate in mechanotransduction in bone cells (40). It has been demonstrated that p38 $\alpha$ MAPK modulates JNK-mediated cell proliferation in myogenesis (41). In addition, the involvement of scavenger receptor class B type 1 in the p38 MAPK signaling pathway is a key mechanism of mediating serum amyloid A-induced angiogenesis in RA (42). Chemokine C-X-C ligand 16 can upregulate receptor activator of nuclear factor $\mathrm{\kappa}-\mathrm{B}$ ligand expression to mediate RA development via the p38/MAPK signaling pathway (43). Wang et al (44) demonstrated that miR-451 suppresses the secretion of inflammatory cytokines and the proliferation of synovial fibroblasts in RA via the p38/MAPK signaling pathway. The results of the current study demonstrated that TNF- $\alpha$ stimulates the Ras/p38 MAPK signaling pathway. By contrast, the inhibition of miR-143-3p suppressed the Ras/p38 MAPK signaling pathway. Given the key role that the Ras/p38 MAPK signaling pathway serves in RA, miR-143-3p may contribute to RA by mediating the Ras/p38 MAPK signaling pathway.

In conclusion, the results of the present study demonstrate that the increased expression of miR-143-3p may contribute to the progression of RA by promoting cell proliferation and inflammatory cytokine secretion, inhibiting the initiation of apoptosis by targeting IGF1R and IGFBP5 and regulating the Ras/p38 MAPK signaling pathway. These results indicate that miR-143-3p may be developed as a potential target for RA therapy. Further studies are required to validate the results of the current study. 


\section{Competing interests}

The authors declare that they have no competing interests.

\section{References}

1. Mertsch S, Schmitz N, Jeibmann A, Geng JG, Paulus W and Senner V: Slit2 involvement in glioma cell migration is mediated by Robo1 receptor. J Neurooncol 87: 1-7, 2008.

2. Challal S, Minichiello E, Boissier MC and Semerano L: Cachexia and adiposity in rheumatoid arthritis. Relevance for disease management and clinical outcomes. Joint Bone Spine 83: $127-133,2016$

3. Ji L, Geng Y, Zhou W and Zhang Z: A study on relationship among apoptosis rates, number of peripheral $\mathrm{T}$ cell subtypes and disease activity in rheumatoid arthritis. Int J Rheum Dis 19: 167-171, 2016.

4. Goldring MB: Osteoarthritis and cartilage: The role of cytokines. Curr Rheumatol Rep 2: 459-465, 2000.

5. Okada Y, Naka K, Kawamura K, Matsumoto T, Nakanishi I, Fujimoto N, Sato H and Seiki M: Localization of matrix metalloproteinase 9 (92-kilodalton gelatinase/type IV collagenase $=$ gelatinase $\mathrm{B}$ ) in osteoclasts: Implications for bone resorption. Lab Invest 72: 311-322, 1995.

6. Symmons DP: Epidemiology of rheumatoid arthritis: Determinants of onset, persistence and outcome. Best Pract Res Clin Rheumatol 16: 707-722, 2002.

7. Muller-Ladner U, Kriegsmann J, Franklin BN, Matsumoto S, Geiler T, Gay RE and Gay S: Synovial fibroblasts of patients with rheumatoid arthritis attach to and invade normal human cartilage when engrafted into SCID mice. Am J Pathol 149: 1607-1615, 1996.

8. Huber LC, Distler O, Tarner I, Gay RE, Gay S and Pap T: Synovial fibroblasts: Key players in rheumatoid arthritis. Rheumatology (Oxford) 45: 669-675, 2006.

9. Lowin T and Straub RH: Synovial fibroblasts integrate inflammatory and neuroendocrine stimuli to drive rheumatoid arthritis. Expert Rev Clin Immunol 11: 1069-1071, 2015.

10. McInnes IB and Schett G: Pathogenetic insights from the treatment of rheumatoid arthritis. Lancet 389: 2328-2337, 2017.

11. Edhayan G, Ohara RA, Stinson WA, Amin MA, Isozaki T, Ha CM, Haines GK III, Morgan R, Campbell PL, Arbab AS, et al: Inflammatory properties of inhibitor of DNA binding 1 secreted by synovial fibroblasts in rheumatoid arthritis. Arthritis Res Ther 18: 87, 2016.

12. Turner JD and Filer A: The role of the synovial fibroblast in rheumatoid arthritis pathogenesis. Curr Opin Rheumatol 27: $175-182,2015$.

13. Gregory RI, Yan KP, Amuthan G, Chendrimada T, Doratotaj B Cooch N and Shiekhattar R: The Microprocessor complex mediates the genesis of microRNAs. Nature 432: 235-240, 2004.

14. Farh KK, Grimson A, Jan C, Lewis BP, Johnston WK, Lim LP, Burge CB and Bartel DP: The widespread impact of mammalian MicroRNAs on mRNA repression and evolution. Science 310: 1817-1821, 2005

15. Ambros V: MicroRNAs and developmental timing. Curr Opin Genet Dev 21: 511-517, 2011

16. Ammari M, Jorgensen C and Apparailly F: Impact of microRNAs on the understanding and treatment of rheumatoid arthritis. Curr Opin Rheumatol 25: 225-233, 2013.

17. Olivieri F, Rippo MR, Procopio AD and Fazioli F: Circulating inflamma-miRs in aging and age-related diseases. Front Genet 4: 121,2013

18. Sugatani T and Hruska KA: Impaired micro-RNA pathways diminish osteoclast differentiation and function. J Biol Chem 284: 4667-4678, 2009.

19. He Z, Yi J, Liu X, Chen J, Han S, Jin L, Chen L and Song H: MiR-143-3p functions as a tumor suppressor by regulating cell proliferation, invasion and epithelial-mesenchymal transition by targeting QKI-5 in esophageal squamous cell carcinoma. Mol Cancer 15: 51, 2016.

20. Soriano-Arroquia A, McCormick R, Molloy AP, McArdle A and Goljanek-Whysall K: Age-related changes in miR-143-3p: Igfbp5 interactions affect muscle regeneration. Aging Cell 15: 361-369, 2016.

21. Schett G, Zwerina J and Firestein G: The p38 mitogen-activated protein kinase (MAPK) pathway in rheumatoid arthritis. Ann Rheum Dis 67: 909-916, 2008.
22. Kawasaki T, Inoue K, Ushiyama T and Fukuda S: Assessment of the American College of Rheumatology criteria for the classification and reporting of osteoarthritis of the knee. Ryumachi 38: 2-5, 1998 (In Japanese).

23. Miyazawa K, Mori A and Okudaira H: Establishment and characterization of a novel human rheumatoid fibroblast-like synoviocyte line, MH7A, immortalized with SV40 T antigen. J Biochem 124: 1153-1162, 1998.

24. Jia Q, Cheng W, Yue Y, Hu Y, Zhang J, Pan X, Xu Z and Zhang P: Cucurbitacin $\mathrm{E}$ inhibits TNF- $\alpha$-induced inflammatory cytokine production in human synoviocyte MH7A cells via suppression of PI3K/Akt/NF-kB pathways. Int Immunopharmacol 29: 884-890, 2015.

25. Chen H, Lin YW, Mao YQ, Wu J, Liu YF, Zheng XY and Xie LP: MicroRNA-449a acts as a tumor suppressor in human bladder cancer through the regulation of pocket proteins. Cancer Lett 320: 40-47, 2012.

26. Zhao X, Liu D, Gong W, Zhao G, Liu L, Yang L and Hou Y: The toll-like receptor 3 ligand, poly(I:C), improves immunosuppressive function and therapeutic effect of mesenchymal stem cells on sepsis via inhibiting MiR-143. Stem Cells 32: 521-533, 2014.

27. Song T, Zhang X, Wang C, Wu Y, Cai W, Gao J and Hong B: MiR-138 suppresses expression of hypoxia-inducible factor 1alpha (HIF-1 $\alpha$ ) in clear cell renal cell carcinoma 786-O cells. Asian Pac J Cancer Prev 12: 1307-1311, 2011.

28. Livak KJ and Schmittgen TD: Analysis of relative gene expression data using real-time quantitative PCR and the 2(-Delta Delta C(T)) method. Methods 25: 402-408, 2001.

29. Ruedel A, Dietrich P, Schubert T, Hofmeister S, Hellerbrand C and Bosserhoff AK: Expression and function of microRNA-188-5p in activated rheumatoid arthritis synovial fibroblasts. Int J Clin Exp Pathol 8: 4953-4962, 2015.

30. Le XF, Merchant O, Bast RC and Calin GA: The roles of MicroRNAs in the cancer invasion-metastasis cascade. Cancer Microenviron 3: 137-147, 2010.

31. Qin H, Tan W, Zhang Z, Bao L, Shen H, Wang F, Xu F and Wang Z: 15d-prostaglandin J2 protects cortical neurons against oxygen-glucose deprivation/reoxygenation injury: Involvement of inhibiting autophagy through upregulation of Bcl-2. Cell Mol Neurobiol 35: 303-312, 2015.

32. Zhang H and Li W: Dysregulation of micro-143-3p and BALBP1 contributes to the pathogenesis of the development of ovarian carcinoma. Oncol Rep 36: 3605-3610, 2016.

33. Wegner N, Lundberg K, Kinloch A, Fisher B, Malmström V, Feldmann $M$ and Venables PJ: Autoimmunity to specific citrullinated proteins gives the first clues to the etiology of rheumatoid arthritis. Immunol Rev 233: 34-54, 2010.

34. Hwang SY, Kim JY, Kim KW, Park MK, Moon Y, Kim WU and Kim HY: IL-17 induces production of IL-6 and IL-8 in rheumatoid arthritis synovial fibroblasts via NF-kappaB- and PI3-kinase/Akt-dependent pathways. Arthritis Res Ther 6: R120-R128, 2004

35. Erlandsson MC, Töyrä Silfverswärd S, Nadali M, Turkkila M, Svensson MND, Jonsson IM, Andersson KME and Bokarewa MI: IGF-1R signalling contributes to IL-6 production and T cell dependent inflammation in rheumatoid arthritis. Biochim Biophys Acta 1863: 2158-2170, 2017.

36. Tardif G, Hum D, Pelletier JP, Duval N and Martel-Pelletier J: Regulation of the IGFBP-5 and MMP-13 genes by the microRNAs miR-140 and miR-27a in human osteoarthritic chondrocytes. BMC Musculoskelet Disord 10: 148, 2009.

37. Zhu C, Qi X, Chen Y, Sun B, Dai Y and Gu Y: PI3K/Akt and MAPK/ERK1/2 signaling pathways are involved in IGF-1-induced VEGF-C upregulation in breast cancer. J Cancer Res Clin Oncol 137: 1587-1594, 2011.

38. Li Z, Li C, Du L, Zhou Y and Wu W: Human chorionic gonadotropin beta induces migration and invasion via activating ERK1/2 and MMP-2 in human prostate cancer DU145 cells. PLoS One 8: e54592, 2013

39. Zhang W and Liu HT: MAPK signal pathways in the regulation of cell proliferation in mammalian cells. Cell Res 12: 9-18, 2002.

40. Liedert A, Kaspar D, Blakytny R, Claes L and Ignatius A: Signal transduction pathways involved in mechanotransduction in bone cells. Biochem Biophys Res Commun 349: 1-5, 2006. 
41. Perdiguero E, Ruiz-Bonilla V, Gresh L, Hui L, Ballestar E, Sousa-Victor P, Baeza-Raja B, Jardí M, Bosch-Comas A, Esteller M, et al: Genetic analysis of p38 MAP kinases in myogenesis: Fundamental role of p38alpha in abrogating myoblast proliferation. EMBO J 26: 1245-1256, 2007.

42. Hong C, Shen C, Ding $\mathrm{H}$, Huang $\mathrm{S}$, Mu Y, Su H, Wei W, Ma J and Zheng F: An involvement of SR-B1 mediated p38 MAPK signaling pathway in serum amyloid A-induced angiogenesis in rheumatoid arthritis. Mol Immunol 66: 340-345, 2015.

43. Li CH, Xu LL, Zhao JX, Sun L, Yao ZQ, Deng XL, Liu R, Yang L, Xing R and Liu XY: CXCL16 upregulates RANKL expression in rheumatoid arthritis synovial fibroblasts through the JAK2/STAT3 and p38/MAPK signaling pathway. Inflamm Res 65: 193-202, 2016.
44. Wang ZC, Lu H, Zhou Q, Yu SM, Mao YL, Zhang HJ, Zhang PC and Yan WJ: MiR-451 inhibits synovial fibroblasts proliferation and inflammatory cytokines secretion in rheumatoid arthritis through mediating p38MAPK signaling pathway. Int J Clin Exp Pathol 8: 14562-14567, 2015.

(i) (9) This work is licensed under a Creative Common

EY No No Attribution-NonCommercial-NoDerivatives 4.0 International (CC BY-NC-ND 4.0) License. 